\title{
Cell-penetrating peptides and their utility in genome function modifications (Review)
}

\author{
MACIEJ GAGAT, WIOLETTA ZIELIŃSKA and ALINA GRZANKA \\ Department of Histology and Embryology, Faculty of Medicine, Nicolaus Copernicus University in Toruń, \\ Collegium Medicum in Bydgoszcz, Pl-85-092 Bydgoszcz, Poland
}

Received July 20, 2017; Accepted September 26, 2017

DOI: $10.3892 / \mathrm{ijmm} .2017 .3172$

\begin{abstract}
For almost 30 years, studies have confirmed the effectiveness of cell-penetrating peptides (CPPs) in the facilitation of the intracellular delivery of various cargo molecules, including RNA, DNA, plasmids, proteins or nanoparticles, under in vitro and in vivo conditions. The cellular uptake of CPPs occurs via energy-dependent, as well as -independent mechanisms. In this relatively new direction of research, studies have attempted to introduce genome modification systems into cells by CPPs. Cellular uptake of CPPs carrying either covalently bound or electrostatically conjugated cargo, has several advantages over viral delivery systems, as it does not lead to any significant cytotoxicity or immunogenicity, and simultaneously it is more efficient than other non-viral systems. So far, CPPs have been successfully used to introduce Cre recombinase, zinc finger nucleases, transcription activator-like effector nucleases and clustered regularly interspaced short palindromic repeats systems into cells. The present article systematically reviewed the information obtained from studies on CPPs and assessed their utility with regard to their effectiveness and safety of use.
\end{abstract}

\section{Contents}

1. Introduction

2. Classification of CPPs

3. Methods for producing CPP-cargo conjugates

4. Mechanism of internalization of CPP

5. Applications of CPPs

6. Toxicity of CPPs

7. Conclusion

Correspondence to: Professor Alina Grzanka, Department of Histology and Embryology, Faculty of Medicine, Nicolaus Copernicus University in Toruń, Collegium Medicum in Bydgoszcz, 24 Karłowicza Street, Pl-85-092 Bydgoszcz, Poland

E-mail: agrzanka@cm.umk.pl

Key words: cell-penetrating peptides, genome engineering, Cre recombinase, zinc finger nucleases, transcription activator-like effector nucleases, cell-penetrating peptide-mediated transduction

\section{Introduction}

Cell-penetrating peptides (CPPs), also known as protein transduction domains (PTDs) or Trojan peptides, are peptides of diverse structure and physicochemical properties. They share two common features. First, they are short peptides containing 5-30 amino acids (1). Furthermore, they have the ability to cross the cell membrane, which is not restricted by their covalent or noncovalent binding of molecules such as DNA (2), RNA (3), antisense oligonucleotides (4), plasmids (5), liposomes (6), proteins (3) or nanoparticles (7). The cellular uptake of CPPs may occur via energy-dependent or -independent mechanisms (1). Due to their low cytotoxicity and immunogenicity, CPPs have been applied in in vitro (8) and in vivo (9) tests with good results. At present, promising results have been obtained primarily for their topical application, while little information on the effects of intravenous administration is currently available. However, predictions are not favorable due to the lack of selectivity of the action of peptides, which may lead to penetration of the cell membrane components of healthy tissue (10).

The discovery of the first CPP was made in 1988 by two independent research groups - Frankel and Pabo (11) and Green and Loewenstein (12). This peptide was derived from the human immunodeficiency virus-1 (HIV-1) TAT protein, a transcriptional transactivator that is essential for HIV-1 replication (13). In 1994, Derossi et al (14) reported that a Drosophila homeobox protein fragment shares the same properties. These studies initiated research into the use of proteins as vectors capable of efficient transport of molecules into the cell and led to the recognition of numerous novel molecules with similar characteristics.

\section{Classification of CPPs}

Based on their origin, CPPs may be divided into three groups: i) Naturally occurring peptides produced by living organisms, ii) chimeric peptides, which are modified natural proteins and iii) synthetic peptides entirely designed and synthesized in the laboratory (15). Specific examples are listed in Table I (11,12,16-20).

Based on their physicochemical properties, CPPs may be also divided into three groups as follows: i) Cationic peptides with an overall positive charge, ii) hydrophobic protein with 
a high content of hydrophobic amino acids such as alanine, methionine or valine and iii) amphipathic proteins, which contain a hydrophobic as well as a hydrophilic fragment (15). Examples for peptides in this classification system are listed in Table II (14,21-25).

Although hundreds of CPPs have already been described in literature, only a few of them are recently used in commercial applications due to insufficient knowledge regarding their properties and mechanism of uptake into cells (26).

\section{Methods for producing CPP-cargo conjugates}

There are two main approaches to introduce CPP-cargo bonds. The first involves the creation of covalent bonds, while the second one comprises the formation of non-covalent bonds. Even though covalent bonding of CPP and cargo is more widespread, it has several disadvantages. First, the chemical reaction, which occurs during the formation of the bond, may modify the properties of the cargo or CPP (27). Furthermore, this method cannot be used to bind plasmids. The solution may be introduction of non-covalent bonds that have been successfully used in the case of combining nucleic acid and protein molecules with short amphipathic penetrating peptides such as MPG (28) or Pep-1 (29). The formation of non-covalent bonds is based on the creation of electrostatic and hydrophobic interactions, which eliminates the risk of changing the biological activity of the bonded molecule by chemical reactions and enables the delivery of plasmid molecules (30). In addition, the non-covalent strategy is simpler in execution, since it only requires incubation of the protein with the transported molecule. It also appears to be an effective and safe means of multiple cargo delivery (31). The effectiveness of interaction between CPP and cargo depends on the peptide/cargo charge ratio, which is the proportion of moles of positively charged amino acid groups in the CPP to those of phosphate ones in the cargo (Fig. 1). In general, a negative to positive (N/P) ratio that is too high results in precipitation or formation of larger particles whose capacity to enter cells is poor, while an N/P ratio that is too low is not effective due to the small capacity of cell internalization (31).

\section{Mechanism of internalization of CPPs}

Despite numerous years of research, the detailed mechanisms of CPP internalization remain to be fully elucidated (15). According to various mechanistic models, it appears that several factors influencing the intake: i) Cell type, ii) mass and structure of the cargo, iii) method of binding, iv) concentration of CPP and v) incubation time and temperature. The diversity in the structure of the cell-penetrating proteins also results in differences in the manner in which the CPP is taken and its effectiveness (32).

Endocytosis and direct translocation are probably the major mechanisms of CPPs entering cells. Endocytosis may occur according to two mechanisms (Fig. 2). The first mechanism is the clathrin-dependent way, which involves the coating of transported molecules by polymerized clathrin. The second mechanism, known as the clathrin-independent mechanism, does not require the presence of clathrin and proceeds through macropinocytosis or via caveolae (33).
Direct translocation, as an energy-independent transport method, is the third of the proposed models. Its validity was confirmed under conditions that prevented endocytosis, e.g. using endocytosis inhibitors (34) and low temperature (35). Despite these factors, effective CPP internalization has been observed (36). The process begins with the interaction of positively charged amino acid residues of unfolded penetrating protein with membrane phospholipids, which interferes with standard interactions between cell membrane components and allows for cell penetration. The protein is then folded again by chaperone action (37). Three alternative mechanisms of direct translocation across the lipid bilayer have also been proposed as follows: i) Inverted micelles, ii) carpet model and iii) pore formation. An inverted micelles variant was described by Derossi et al (16) based on the results of nuclear magnetic resonance imaging of penethrin internalization. This hypothetical mechanism starts with the interaction of cationic amino acid residues with negatively charged phospholipid groups, but in this case, it leads to the production of micelles by the phospholipids which are enclosing the peptide. The presence of hydrophobic amino acids in the peptide is also required for this process. The micelle then reopens inside the cell and releases the protein (38). In the carpet model, internalization takes place in three stages. The first involves interactions of cationic residues of proteins with phospholipids, leading to changes in membrane structure. In the next step, a rotation of the peptide occurs, enabling the interaction of hydrophobic protein residues with hydrophobic tails of phospholipids. Finally, CPP penetrates the membrane by the slight disturbances caused during the second stage. It is also a mechanism by which certain antibacterial substances, including magainins, exert their toxic effects (39). The third model comprises pore formation, which may occur due to creation of bonds between the hydrophobic part of an amphipathic $\alpha$-helical penetrating peptide with the lipid part of the membrane. As a result, the hydrophilic residues produce pores that allow this molecule to penetrate the membrane (40).

So far, it has not been determined which of these models represent the true processes of CPP uptake. It is also likely that conditions of the cellular environment affect the way in which CPPs internalize the cell. It is possible that several modes of internalization occur at the same time (32).

\section{Applications of CPPs}

CPPs are widely used in studies on methods for transporting therapeutic particles through the cell membrane. Numerous studies have confirmed their potential in vitro and in vivo $(10,41)$. Using CPPs, molecules including proteins (3), liposomes (6) and nanoparticles (7) have already been introduced into cells with satisfying results. However, CPPs may also be used for the internalization of nucleic acids $(2,4,5)$. After numerous successful preclinical studies, certain CPPs, including TAT and its conjugates, have entered phase-I, phase-II or even phase-III clinical trials. Data obtained from these studies proved that the use of CPPs for clinical therapy is possible, as they are well tolerated and directed to intracellular targets. So far, penetrating peptides have been used in clinical trials, including those on the treatment of cardiovascular diseases (42), pain (43-45), hearing loss (46) and even facial 
Table I. Examples of cell-penetrating peptides classified on the basis of their origin with indication of their sequence and key feature.

\begin{tabular}{|c|c|c|c|c|}
\hline $\begin{array}{l}\text { Protein } \\
\text { group }\end{array}$ & $\begin{array}{l}\text { Protein } \\
\text { name }\end{array}$ & Sequence & Characteristics & Refs. \\
\hline Natural & $\begin{array}{l}\text { TAT } \\
\text { pVEC }\end{array}$ & $\begin{array}{l}\text { GRKKRRQRRRPPQ } \\
\text { LLIILRRRIRKQAHAHSK }\end{array}$ & $\begin{array}{l}\text { Transcriptional regulator of HIV. } \\
\text { Mouse's catherin sequence. }\end{array}$ & $\begin{array}{l}(11,12) \\
(16)\end{array}$ \\
\hline \multirow[t]{2}{*}{ Chimeric } & Transportan & GWTLNSAGYLLGKINLKALAALAKKIL & $\begin{array}{l}\text { Protein formed by the combination } \\
\text { of neuropeptide galanin and } \\
\text { wasp's botulinum toxin, mastoparan, } \\
\text { through a lysine residue. }\end{array}$ & $(17)$ \\
\hline & MPG & GALFLGFLGAAGSTMGAWSQPKKKRKV & $\begin{array}{l}\text { Protein obtained by the fusion of } \\
\text { the transmembrane glycoprotein of HIV, } \\
\text { gp41, with SV40 virus T-antigen. }\end{array}$ & $(18)$ \\
\hline \multirow[t]{2}{*}{ Synthetic } & MAP & KLALKLALKALKAALKLA & $\begin{array}{l}\text { Amphipathic protein created de novo from } \\
\text { lysine, arginine and leucine residues. }\end{array}$ & $(19)$ \\
\hline & $\mathrm{R}_{6} \mathrm{~W}_{3}$ & RRWWRRWRR & $\begin{array}{l}\text { Artificial peptide created de novo based } \\
\text { on the structure of penetrin. }\end{array}$ & (20) \\
\hline
\end{tabular}

pVEC, 18 amino acid CPP derived from murine vascular endothelial-cadherin; HIV, human immunodeficiency virus; MAP, model amphipathic protein.

Table II. Examples of cell-penetrating peptides classified on the basis of their physicochemical properties with indication of their sequence and key features.

\begin{tabular}{|c|c|c|c|c|}
\hline $\begin{array}{l}\text { Protein } \\
\text { group }\end{array}$ & $\begin{array}{l}\text { Protein } \\
\text { name }\end{array}$ & Sequence & Characteristics & Refs. \\
\hline \multirow[t]{2}{*}{ Cationic } & R9 & RRRRRRRRR & $\begin{array}{l}\text { Synthetically created sequence } \\
\text { of nine arginines. }\end{array}$ & $(21)$ \\
\hline & Antp & RQIKIWFQNRRMKWKK & $\begin{array}{l}\text { Homeobox gene of } \\
\text { Drosophila melanogaster, which } \\
\text { determines the development } \\
\text { of the morphological } \\
\text { differences between } \\
\text { the segment of head } \\
\text { and torso of the insect. }\end{array}$ & $(14)$ \\
\hline \multirow[t]{2}{*}{ Hydrophobic } & VP22 & DAATATRGRSAASRPTERPRAPARSASRPRRVD & $\begin{array}{l}\text { A component of a capsid } \\
\text { of HSV-1 virus. }\end{array}$ & $(22)$ \\
\hline & K-FGF & AAVLLPVLLAAP & $\begin{array}{l}\text { Artificial peptide containing } \\
\text { the penetrating motif and locating } \\
\text { the cell nucleus sequence. }\end{array}$ & $(23)$ \\
\hline \multirow[t]{2}{*}{ Amphipathic } & VT5 & DPKGDPKGVTVTVTVTVTGKGDPKPD & Capsid protein of rotaviruses & $(24)$ \\
\hline & SynB1 & RGGRLSYSRRRFSTSTGR & $\begin{array}{l}\text { The peptide derived from protegrin. } \\
\text { It has the ability to cross } \\
\text { the blood-brain barrier. }\end{array}$ & $(25)$ \\
\hline
\end{tabular}

Antp, the third helix of the homeotic protein of Drosophila melanogaster Antennapedia; HSV, herpes simplex virus; VP22, herpes simplex virus protein VP22; K-FGF, Kaposi fibroblast growth factor.

wrinkles (47). One of the first phase-III clinical trials that reached completion included the use of TAT in combination with a c-Jun N-terminal kinase inhibitor. In 2012, a TAT-coupled dextrogyre peptide inhibiting the c-Jun N-terminal kinase, named XG-102, successfully passed a phase-I clinical trial, which was designed to determine the safety of its use, and did 

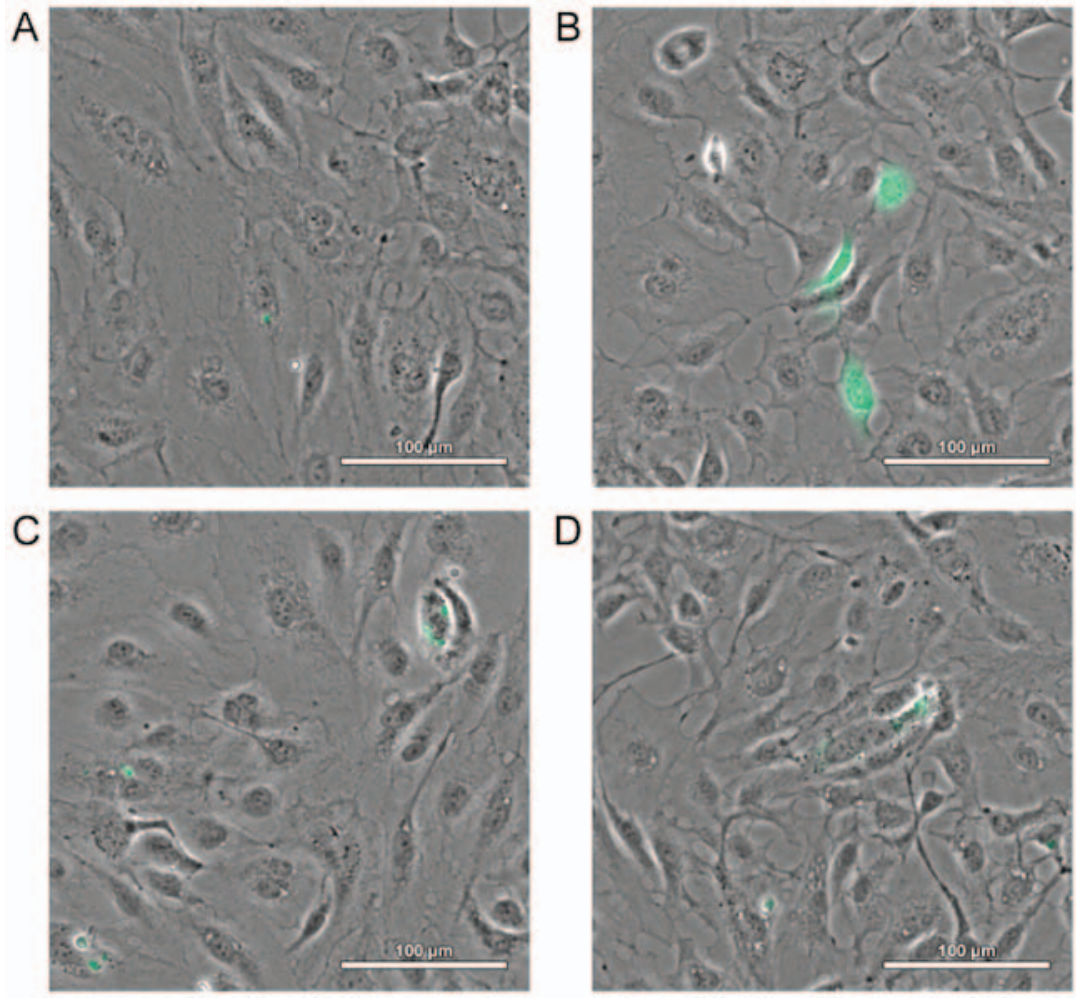

Figure 1. Expression of GFP in primary human carotid artery endothelial cells at $24 \mathrm{~h}$ after transfection with electrostatic complex of basic domain $47-57$ of HIV-1 trans-activating protein [HIV TAT (47-57)] and pmaxGFP plasmid DNA at different CRs using $1 \mu \mathrm{g}$ of plasmid DNA (scale bar, $100 \mu \mathrm{m}$ ). (A) CR=2:1, (B) $\mathrm{CR}=4: 1$, (C) $\mathrm{CR}=8: 1$, (D) $\mathrm{CR}=16: 1$. GFP, green fluorescent protein; CR, charge ratio; HIV, human immunodeficiency virus.

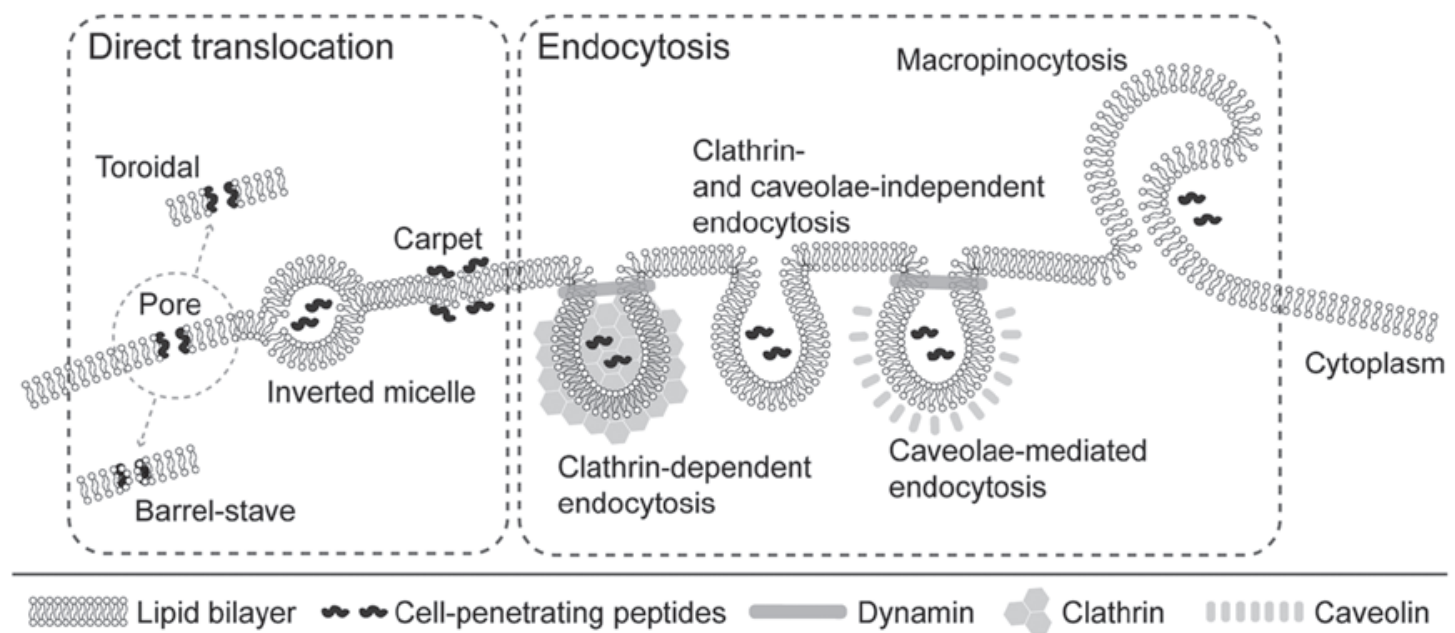

Figure 2. Mechanisms of cellular internalization of CPPs. Different mechanisms of cellular uptake of CPPs have been proposed. These mechanisms include direct translocation and endocytosis. Several models have been proposed for direct translocation: i) Formation of transient pores (the toroidal pore model, where CPPs interact with polar groups of membrane phospholipids, and the barrel stave model, where CPPs assume an amphipathic $\alpha$-helix structure when inserted into the cellular membrane); ii) inverted micelles, where CPPs disturb the lipid bilayer, leading to the formation of inverted hexagonal structures, and iii) the carpet model, where CPPs transiently destabilize the cellular membrane by their association to its surface, leading to the reorganization of phospholipids. Uptake of CPPs through the cell membrane was demonstrated to proceed via several endocytotic pathways: i) Clathrin-dependent, ii) clathrin- and caveolae-independent, and iii) caveolae-mediated. In addition, CPPs may be internalized by macropinocytosis. CPPs, cell-penetrating peptides.

not produce any adverse effects other than those induced by the placebo (48). The phase-III trial was aimed at assessing the ability of the substance to inhibit intraocular inflammation and reduce pain in patients undergoing cataract surgery. That phase was completed in 2015 and demonstrated the absence of anterior chamber cells and pain (49). Another member of the c-Jun $\mathrm{N}$-terminal kinase inhibitor family conjugated with
TAT has been used in a study on the treatment of hearing loss. After the success of the phase-I trial (46), compound AM-111 created by Auris Medical is currently being investigated in two phase-III clinical trials $(50,51)$.

Transport of nucleic acids. Nucleic acid molecules such as small interfering RNA (siRNA), antisense oligonucleotides, 
decoy DNA or plasmids are widely used in the gene therapy of numerous diseases. The current drawbacks include low efficiency of cell uptake and low bioavailability of the therapeutic nucleic acid molecules alone (52). These inconveniences may be overcome by the use of penetrating proteins (53).

Numerous available CPPs have been used to transport siRNA particles; these include MPG (28), transportan (54) and TAT (55). Penetrating peptides may be covalently or non-covalently conjugated with siRNA. The covalent approach is suitable to provide only one siRNA particle conjugated to one peptide particle. However, there are several problems associated with this method. First, the bonding is required to be reversible within the cell's environment. Furthermore, cationic CPPs form non-covalent bonds with siRNA and the large aggregates are created involuntarily (27). In addition, the efficacy of the uptake is insufficient, probably due to neutralization of the positive charge of the cationic peptide, which is necessary to disrupt cell membrane, by the negative charge of the siRNA (30). The problem of aggregation may be overcome by addition of denaturing agent, e.g. formamide (56). Only a few studies on CPP, siRNA conjugates have been published. The most widely used method of preparation is the chemical synthesis of disulfide-linked CPP conjugates of oligonucleotides, the bond of which is impermanent in the reducing environment of the cytosol. Muratovska and Eccles (57) confirmed that delivery of siRNA against luciferase or enhanced green fluorescent protein (EGFP) mRNA fused with penetrin or transportan via a disulfide bond reduced the expression of these genes in transfected cell lines more efficiently than Lipofectamine/siRNA complex. The same type of bond was successfully used by Davidson et al (58). They demonstrated the introduction of siRNA-targeting caspases and superoxide dismutase into primary hippocampal neuronal cells using penetratin 1 . This study was particularly important because of the small selection of tools for introducing molecules into highly specialized neuronal cells (58). One problem with the above studies is the lack of a purification step for conjugates prepared by a non-specific oxidation method (56). Another approach was applied by Chiu et al (59). They used a stable thiol-maleimide linkage and also purification of conjugates by denaturing gels or reverse-phase high-performance liquid chromatography. The study demonstrated that TAT 47-57 peptide or TAT 47-57-derived oligocarbamate and siRNA against EGFP or endogenous cyclin-dependent kinase 9 inhibited the expression of reporter as well as endogenous genes with satisfying results, but again, as indicated by Turner et al (60), the efficiency of the purification process was not evaluated. Uptake of the conjugates was similar to that obtained by the application of Lipofectamine (59). The purification step may also be performed by using anion exchange chromatography with addition of a denaturing agent (60).

Although covalent conjugation of CPP to cargo has proven to be effective, a much simpler and equally effective method is available: Non-covalent binding, which includes formation of electrostatic and hydrophobic interactions between cargo and CPP. This approach has several advantages. First, it is easy to use, as it only requires simple incubation of penetrating peptide and cargo. In addition, there is no chemical reaction, and therefore, there is no risk of any undesirable cargo structure or activity modification (61). While covalent conjugates appear to cross the membrane via an endosomal pathway, the mechanism of internalization of non-covalent complexes still remains to be elucidated (62). The most widely used class of CPPs for non-covalent binding of siRNA is an amphipathic class, which includes MPG (63), Pep-1 (64) or CADY (62). The MPG-8 protein, which is a shorter version of MPG, was used to deliver siRNA against cyclin B1 mRNA in a murine model of human prostate tumor (63). Cyclin B1 is responsible for cyclin-dependent kinase 1 activation. The delivery of siRNA against cyclin B1 conjugated to MPG-8 led to the blockage of tumor cell proliferation as a result of cell cycle arrest in G2 phase (63). siRNA is also an effective tool to inhibit HIV-1 replication within infected cells, but this requires an effective delivery system. It was proven that a chimeric peptide composed of CPP as an RNA-binding domain and cell fusion peptide domain combined with siRNA entered the cells and inhibited HIV-1 replication (65).

CPPs are not only of use for inhibiting the expression of genes by delivering siRNA, but also for introducing additional genetic material, e.g. plasmid DNA. The widely used CPP Arg nonapeptide (R9) was demonstrated to be a more efficient tool for plasmid delivery than the commercially available transfection reagent TurboFect (66). Another study also reported that TAT is capable of transferring plasmids into cells (67).

CPPs in genome editing. In addition to positive or negative regulation of gene products, CPPs may be used for genome editing. Cre recombinase, zinc-finger nucleases (ZFNs), transcription activator-like effector nucleases (TALENs) and clustered regularly interspaced short palindromic repeats (CRISPR)/Cas 9 are currently the most widespread tools for genome engineering. CPPs may be used to deliver all of them into cells (68).

The Cre/locus of $\mathrm{X}$ (cross)-over in P1 (LoxP) system is a promising tool for editing specific DNA sequences. The cleavage location is determined by the short LoxP sequences below and above the removed sequence in reverse orientation. The reaction of cleavage is catalyzed by Cre recombinase derived from bacteriophage $\mathrm{P}$. This tool is attractive, as insertion of Cre recombinase under the control of an inducible promoter may allow the site-specific excretion of a particular gene. However, the problem with this method is the selection of an appropriate Cre/LoxP delivery system (69). The first successful attempt to introduce Cre recombinase into the cell using penetrating peptides was made in 2001 by Jo et al (70). They used purified recombinant fusion proteins bearing the 12 amino acid membrane translocation sequence (MTS) from Kaposi fibroblast growth factor to deliver enzymatically active Cre proteins directly into NIH3T3 and S4R murine embryonic stem cells with a single loxP-modified sulfonylurea receptor gene, and the Tex.loxP.EG cell line was generated by Cre-mediated recombination activating the expression of a GFP reporter gene following delivery via this system. Of the four recombinant proteins investigated glutathione-S-transferase (GST)-Cre-MTS, GST-nuclear localization signal (NLS)-Cre-MTS, maltose-binding proteinNLS-Cre-MTS and His6-NLS-Cre-MTS), the best result was obtained using His6-NLS-Cre-MTS. Recombination was induced in $82 \%$ of Tex.loxp.EG cells following three consecutive 2-h treatments with $10 \mu \mathrm{M}$ His6-NLS-Cre-MTS. In the same study, the in vivo activity of His6-NLS-Cre-MTS was 
tested in ROSA26R mice. ROSA26R is a transgenic mouse strain in which a $\beta$-galactosidase reporter gene is activated by Cre-mediated recombination. It was demonstrated that recombination induced by His6-NLS-Cre-MTS occurred in $~ 50 \%$ of splenocytes cultured in the absence of lipopolysaccharide. In addition, in mice injected with His6-NLS-Cre-MTS once a day for three days, Cre-mediated recombination without any side effect was observed in all examined tissues, including the brain, heart, kidney, lung, spleen and liver (70). In another study, reporter T cells were also used to determine the mechanism of TAT-Cre internalization. Despite the strong binding of TAT to the cell surface, indicating a direct penetration mechanism, the protein was revealed to enter the cell via multistep mechanism. Wadia et al (71) suggested that TAT CPP-mediated cellular entry occurs by interaction with lipid rafts in a receptorindependent manner and subsequent rapid internalization by macropinocytosis, followed by a $\mathrm{pH}$ drop and disintegration of the lipid bilayer of the macropinosome, resulting in cargo release from TAT into the cytosol (71). Furthermore, Hashimoto et al (72) reported that Cre-mediated recombination of genomic targets takes places principally during the S-phase of the cell cycle. This is probably due to the relaxation of the chromatin structure during $\mathrm{S}$-phase, which enhances the attachment of Cre to the DNA molecule and increases the $\mathrm{Cre} /$ loxP recombination reaction. Xu et al (73) have confirmed the safety of Cre recombinase in combination with TAT, as there were no significant changes in cell proliferation or the karyotype of transgenic goat fibroblasts after incubation with TAT-Cre. In addition, TAT-Cre did not alter the developmental competence of embryos reconstructed by nuclear transfer from TAT-Cre-transduced cells. Furthermore, they obtained two live transgenic goats with no evident abnormalities in development or behavior for at least 3 months after birth (73).

The CPP and Cre conjugates have been successfully applied to numerous cell lines, including HeLa, Rp250 and HEK-283 (74), and also in organotypic cultures derived from adult mice and embryos carrying a reporter gene flanked by LoxP sequences (75). In vivo studies demonstrating their usefulness are also available. Sonsteng et al (76) proved that Cre fused with TAT enters hepatocytes of mice following tail vein injection. For this purpose, two types of mice were used. The first one was ROSA ${ }^{\mathrm{mT}-\mathrm{mG}}$, whose cells exhibit red membrane fluorescence in the absence of Cre or strong membrane expression of EGFP in the presence of Cre. The second one was ROSA ${ }^{\mathrm{nT}-\mathrm{nG}}$, which differs from ROSA ${ }^{\mathrm{mT}-\mathrm{mG}}$ in nuclear localization of red- and GFP in the absence or presence of Cre, respectively. They demonstrated that after TAT-Cre administration, 5-20\% of hepatocytes were converted, which provided a more effective conversion of centrolobular hepatocytes than in mice hydrodynamically inoculated with pMC1-Cre plasmid. Recombination occurred only in hepatocytes, and was not observed in endothelial other non-hepatocyte cells in the liver or in any other organs. However, in animals inoculated with TAT-Cre cells exhibiting green fluorescence were identified near the injection site in the tail (76).

Although in engineered site-directed nucleases, such as ZFNs, delivery of components into the cells is not a significant problem, as it has been proven that purified ZFNs have the ability to be internalized by cells independently (77); however, the use of CPPs enhances the uptake efficiency (78). The major problems with using ZFNs are their cytotoxicity and off-target effects (79). These may also be potentially reduced by using CPP (80). So far, CPP-ZFN conjugates have been applied in approaches towards treating breast cancer (81) and malaria (82). CPPs conjugated to mammalian target of rapamycin (mTOR)-specific ZFN have been proposed as a novel therapeutic approach to disrupt the gene function of mTOR (81). The phosphoinositide-3 kinase/Akt/mTOR pathway is essential for growth and proliferation of breast cancer cells. It has been suggested that elimination of the effect of mTOR in sustaining the survival of cancerous cells may inhibit this pathway and result in slower tumor growth. ZFN-CPP has also been proposed as a safe drug which may help to eliminate parasites from infected cells (82). However, only an in vitro study is currently available.

Introducing transcription activator-like effector nucleases (TALENs) into cells is slightly more challenging due to reasons including its molecular weight. TALENs do not contain the Cys2-His2 zinc-finger domain, which allows for direct penetration of the cell membrane by ZFNs (83). For this purpose, CPPs have already been adapted with satisfying results in in vitro studies and they are a promising alternative to current methods for the delivery of TALENs into mammalian cells. Liu et al (83) demonstrated that TALEN conjugated to poly-Arg peptides enters the cells and, without any obvious toxicity, is able to induce gene knockout in human cell lines. They proved that HeLa cells incubated for $2 \mathrm{~h}$ with R9-conjugated C-C chemokine receptor type 5 (CCR5) targeting TALEN protein resulted in CCR5 gene disruption at a frequency that was three times higher than that achieved by transient transfection of TALEN expression vectors, while the process did not cause any significant decrease in cell viability. The reaction was most effective with peptide/protein ratios of 8:1 and 15:1. At lower ratios, R9 was probably unable to penetrate the cell membrane efficiently, whereas at higher peptide/ protein ratios, no complete breakdown of bonds between CPP and cargo occurred and these ratios were not effective during internalization of TALEN designed to knock down the bone morphogenetic protein receptor type IA gene in the HEK293 cell line (83). This suggests that different types of these nucleases require different peptide-to-protein ratios. However, the penetrating abilities of penetrin, transportan and human growth hormone-1 connected with TALEN were not observed. Another CPP with proven efficacy in TALEN delivery was TAT. It was used for disruption of the CCR5 gene in HeLa cells and human induced pluripotent stem cells under hypothermic conditions (83).

CRISPR, which is associated with nucleases from Cas family, naturally occurs as a part of the adaptive immune system against bacteria and archaea. The effect of CRISPR is based on storing fragments of exogenous DNA harvested, e.g. during bacteriophage infection, from the bacterial genome for quick recognition and destruction of DNA molecules containing this fragment by nucleases in case of further infection (84). This method, as an RNA-guided way of DNA cutting, has been successfully applied in the genome modification of bacteria (85), cell cultures (3), animals (86) and plants (87). Derived from the CRISPR/Cas system, RNA-guided nuclease consists of two major components - Cas9 protein and guide RNA (gRNA). Efficient delivery of these two types of particle 
is necessary for gene editing and these components may be introduced into the cell using lentiviral and adeno-associated viral systems, which have the potential for random integration of vector sequence into the host genome, leading to undesirable changes $(88,89)$. For this reason, a virus- and plasmid-free approach has been developed. Cas9 and gRNA have been delivered separately as CPP-conjugated Cas9 and CPP-complexed gRNA. This approach led to a lesser degree of off-target mutations and immune responses in the host, and also induced lower cytotoxicity (89). Ramakrishna et al (3) reported on the preparation of a modified sequence of the Cas 9 gene, its ligation within plasmid pET-28a(+), introduction of the plasmid into Escherichia coli BL21, and isolation and purification of the resulting protein. The modified Cas9 protein contained cysteine at the $\mathrm{N}$-terminus, which allowed for the attachment of 4-maleimidobutyryl-4G9R4L (m9R) via a thioether bond between the free $\mathrm{SH}$ residue of $\mathrm{C}$-terminal cysteine of Cas9 and the primary amine residue $\left(-\mathrm{NH}_{2}\right)$ of $\mathrm{m} 9 \mathrm{R}$, whereas the single guide RNA (sgRNA)-9R complex was formed by incubation of the components at room temperature for $30 \mathrm{~min}$ (3). In addition, the introduction of sgRNA as a complex with CPP may potentially enable the simultaneous introduction of several of its type, and thus the system's functioning at several locations in the genome.

\section{Toxicity of CPPs}

The cytotoxic effects of peptides depend on their amino acid sequence, secondary structure and summary charge (90). Abnormalities that may be caused by CPPs include cytoplasmic leakages due to changes in membrane permeability, and dysfunction in membrane proteins resulting from interactions with amphipathic CPPs (91). Cellular membrane permeability was examined by measuring the leakage of lactate dehydrogenase (LDH) in several cell lines, K562 (erythroblastic leukemia), MDA-MB-231 (breast cancer) and immortalized endothelial cells from an aorta (91). Saar et al (91) reported that incubation with the model amphipathic protein and trasportan 10 resulted in a significant increase of LDH leakage in the two tumor cell lines but did not produce any statistically significant changes in the endothelial cell line. In addition, cationic peptides, including penetrin, an 18 amino acid CPP derived from murine vascular endothelial-cadherin (pVEC) and TAT, did not induce any cytotoxicity (91). The mechanisms of the selective action of amphipathic CPPs on tumor cells have remained to be elucidated. However, they appear to be a good choice for the treatment of oncological patients. Of note, none of the proteins caused any significant hemolysis, which confirms the relative safety of their use (91).

In general, in vitro and in vivo experiments demonstrated that CPPs did not induce any significant cytotoxic effect, even at high concentrations (92). The behavior, appearance and eating habits of the animals were examined prior to and after administration of various doses of CPP-phosphorodiamidate morpholino oligomer conjugates (93). The body weight and serum levels of urea were also measured. In rats receiving the conjugate at $15 \mathrm{mg} / \mathrm{kg}$ body weight, no changes in any of the parameters were observed. In those receiving $30 \mathrm{mg} / \mathrm{kg}$ body weight, a slight decrease in body weight and an increase in urea levels in the serum were observed, but these changes were not health-threatening. No dose lower than $150 \mathrm{mg} / \mathrm{kg}$ body weight caused any weight loss or significant deterioration of any biochemical indicators. Approximately 50\% mortality of animals occurred in the groups receiving 210 and $250 \mathrm{mg} / \mathrm{kg}$ and $100 \%$ mortality was observed in those receiving $400 \mathrm{mg} / \mathrm{kg}$ body weight of the conjugate. These studies also confirm the safety of the use of CPP, as no significant adverse effects were noticeable at doses sufficient for therapeutic purposes ( $\leq 15 \mathrm{mg} / \mathrm{kg}$ ) (93). The toxicity of CPPs may also be affected by the presence of the cargo. However, Maiolo et al (94) demonstrated that free R7 and R7W exhibited slightly higher toxicity than those associated with cargo.

\section{Conclusion}

Gene modification systems, e.g. Cre recombinase, ZFNs, TALENs or CRISPRs, provide the possibility of effective treatment of diseases that have been so far considered as incurable. One of the problems with using these methods is to identify an appropriate system for their transport through the cell membrane. Viral delivery systems, in spite of being most effective, generate abnormalities such as immunogenicity or cytotoxicity. Another disadvantage is the limited size of the insert. On the other hand, non-viral systems, including electroporation or liposomes, do not cause any immune reactions, and within certain limits, the size of the transported molecule has no effect; however, they also have certain disadvantages. The major disadvantage is a lower transduction efficiency $(95,96)$. The lack of an ideal tool for introducing molecules into cells motivated researchers to search for novel and improved methods. In this light, CPPs were discovered as a promising alternative to current methods. As a non-viral system, CPP-cargo complexes are characterized by safety of use, while maintaining a relatively high efficiency. For this reason, they are used in genome editing studies with better results than those achieved for other non-viral methods $(57,66)$. However, certain problems remain to be solved prior to any clinical trials being performed on delivery of genome modification systems by CPPs, especially after promising trials with other cargoes. First of all, the mechanisms by which CPPs penetrate the cell membrane requires to be fully elucidated. It would also be useful to determine the impact of CPPs on organisms after intravenous administration, most results available were obtained by studies applying local administration. Further research on the selection of suitable conditions for the production of conjugates or complexes of CPP and cargo, as well as appropriate cell incubation protocols should be performed to fully exploit the potential of CPPs and to achieve maximum efficiencies.

\section{Acknowledgements}

This study was supported by a grant from the National Science Centre, Poland (grant no. 2015/17/D/NZ7/00809 to M.G.).

\section{References}

1. Zorko $\mathrm{M}$ and Langel U: Cell-penetrating peptides: Mechanism and kinetics of cargo delivery. Adv Drug Deliv Rev 57: 529-545, 2005.

2. Karro K, Männik T, Männik A and Ustav M: DNA transfer into animal cells using stearylated CPP based transfection reagent. Methods Mol Biol 1324: 435-445, 2015. 
3. Ramakrishna S, Kwaku Dad A-BB, Beloor J, Gopalappa R, Lee SK and Kim H: Gene disruption by cell-penetrating peptide-mediated delivery of Cas9 protein and guide RNA. Genome Res 24: 1020-1027, 2014.

4. Zatsepin TS, Turner JJ, Oretskaya TS and Gait MJ: Conjugates of oligonucleotides and analogues with cell penetrating peptides as gene silencing agents. Curr Pharm Des 11: 3639-3654, 2005.

5. Segovia N, Dosta P, Cascante A, Ramos V and Borrós S: Oligopeptide-terminated poly( $\beta$-amino ester)s for highly efficient gene delivery and intracellular localization. Acta Biomater 10: 2147-2158, 2014

6. Liu C, Luo Q, Tu Y, Wang G, Liu Y and Xie Y: Drug-carrier interaction analysis in the cell penetrating peptide-modified liposomes for doxorubicin loading. J Microencapsul 32: 745-754, 2015.

7. Li Y, Wen G, Wang D, Zhang X, Lu Y, Wang J, Zhong L, Cai H, Zhang X and Wang Y: A complementary strategy for enhancement of nanoparticle intracellular uptake. Pharm Res 31: 2054-2064, 2014.

8. Jo J, Hong S, Choi WY and Lee DR: Cell-penetrating peptide (CPP)-conjugated proteins is an efficient tool for manipulation of human mesenchymal stromal cells. Sci Rep 4: 4378, 2014.

9. Khafagy S, Morishita M, Isowa K, Imai J and Takayama K: Effect of cell-penetrating peptides on the nasal absorption of insulin. J Control Release 133: 103-108, 2009.

10. Skotland T, Iversen TG, Torgersen ML and Sandvig K Cell-penetrating peptides: Possibilities and challenges for drug delivery in vitro and in vivo. Molecules 20: 13313-13323, 2015.

11. Frankel AD and Pabo CO: Cellular uptake of the tat protein from human immunodeficiency virus. Cell 55: 1189-1193, 1988.

12. Green M and Loewenstein PM: Autonomous functional domains of chemically synthesized human immunodeficiency virus tat trans-activator protein. Cell 55: 1179-1188, 1988

13. Ruben S, Perkins A, Purcell R, Joung K, Sia R, Burghoff R, Haseltine WA and Rosen CA: Structural and functional characterization of human immunodeficiency virus tat protein. J Virol 63: 1-8, 1989.

14. Derossi D, Joliot AH, Chassaing G and Prochiantz A: The third helix of the Antennapedia homeodomain translocates through biological membranes. J Biol Chem 269: 10444-10450, 1994.

15. Milletti F: Cell-penetrating peptides: Classes, origin, and current landscape. Drug Discov Today 17: 850-860, 2012.

16. Derossi D, Chassaing G and Prochiantz A: Trojan peptides: The penetratin system for intracellular delivery. Trends Cell Biol 8: 84-87, 1998.

17. Pooga M, Hällbrink M, Zorko M and Langel U: Cell penetration by transportan. FASEB J 12: 67-77, 1998.

18. Kwon SJ, Han K, Jung S, Lee JE, Park S, Cheon YP and Lim HJ: Transduction of the MPG-tagged fusion protein into mammalian cells and oocytes depends on amiloride-sensitive endocytic pathway. BMC Biotechnol 9: 73, 2009.

19. Mo RH, Zaro JL and Shen WC: Comparison of cationic and amphipathic cell penetrating peptides for siRNA delivery and efficacy. Mol Pharm 9: 299-309, 2012.

20. Bechara C, Pallerla M, Burlina F, Illien F, Cribier S and Sagan S Massive glycosaminoglycan-dependent entry of Trp-containing cell-penetrating peptides induced by exogenous sphingomyelinase or cholesterol depletion. Cell Mol Life Sci 72: 809-820, 2015.

21. Melikov K, Hara A, Yamoah K, Zaitseva E, Zaitsev E and Chernomordik LV: Efficient entry of cell-penetrating peptide nona-arginine into adherent cells involves a transient increase in intracellular calcium. Biochem J 471: 221-230, 2015.

22. Zavaglia D, Favrot MC, Eymin B, Tenaud C and Coll JL: Intercellular trafficking and enhanced in vivo antitumour activity of a non-virally delivered P27-VP22 fusion protein. Gene Ther 10: 314-325, 2003

23. Lin YZ, Yao SY, Veach RA, Torgerson TR and Hawiger J: Inhibition of nuclear translocation of transcription factor NF-kappa B by a synthetic peptide containing a cell membranepermeable motif and nuclear localization sequence. J Biol Chem 270: 14255-14258, 1995

24. Oehlke J, Krause E, Wiesner B, Beyermann M and Bienert M: Extensive cellular uptake into endothelial cells of an amphipathic beta-sheet forming peptide. FEBS Lett 415: 196-199, 1997.

25. Rousselle C, Clair P, Temsamani J and Scherrmann JM: Improved brain delivery of benzylpenicillin with a peptide-vector-mediated strategy. J Drug Target 10: 309-315, 2002.

26. Järver $P$ and Langel U: Cell-penetrating peptides - a brief introduction. Biochim Biophys Acta 1758: 260-263: 2006.
27. Meade BR and Dowdy SF: Exogenous siRNA delivery using peptide transduction domains/cell penetrating peptides. Adv Drug Deliv Rev 59: 134-140, 2007.

28. Simeoni F, Morris MC, Heitz F and Divita G: Insight into the mechanism of the peptide-based gene delivery system MPG: Implications for delivery of siRNA into mammalian cells. Nucleic Acids Res 31: 2717-2724, 2003.

29. Muñoz-Morris MA, Heitz F, Divita G and Morris MC: The peptide carrier Pep-1 forms biologically efficient nanoparticle complexes. Biochem Biophys Res Commun 355: 877-882, 2007.

30. Gros E, Deshayes S, Morris MC, Aldrian-Herrada G, Depollier J, Heitz F and Divita G: A non-covalent peptide-based strategy for protein and peptide nucleic acid transduction. Biochim Biophys Acta 1758: 384-393, 2006

31. Deshayes S, Morris M, Heitz F and Divita G: Delivery of proteins and nucleic acids using a non-covalent peptide-based strategy. Adv Drug Deliv Rev 60: 537-547, 2008.

32. Guo Z, Peng H, Kang J and Sun D: Cell-penetrating peptides: Possible transduction mechanisms and therapeutic applications. Biomed Rep 4: 528-534, 2016.

33. Mäger I, Langel K, Lehto T, Eiríksdóttir E and Langel U: The role of endocytosis on the uptake kinetics of luciferin-conjugated cell-penetrating peptides. Biochim Biophys Acta 1818: 502-511, 2012.

34. Dutta D and Donaldson JG: Search for inhibitors of endocytosis: Intended specificity and unintended consequences. Cell Logist 2: 203-208, 2012

35. Tomoda H, Kishimoto Y and Lee YC: Temperature effect on endocytosis and exocytosis by rabbit alveolar macrophages. J Biol Chem 264: 15445-15450, 1989.

36. Bode SA1, Thévenin M, Bechara C, Sagan S, Bregant S, Lavielle S, Chassaing $\mathrm{G}$ and Burlina F: Self-assembling mini cell-penetrating peptides enter by both direct translocation and glycosaminoglycan-dependent endocytosis. Chem Commun (Camb) 48: 7179-7181, 2012.

37. Cleal K, He L, Watson PD and Jones AT: Endocytosis, intracellular traffic and fate of cell penetrating peptide based conjugates and nanoparticles. Curr Pharm Des 19: 2878-2894, 2013.

38. Derossi D, Calvet S, Trembleau A, Brunissen A, Chassaing G and Prochiantz A: Cell internalization of the third helix of the Antennapedia homeodomain is receptor-independent. J Biol Chem 271: 18188-18193, 1996.

39. Matsuzaki K, Sugishita K and Miyajima K: Interactions of an antimicrobial peptide, magainin 2, with lipopolysaccharidecontaining liposomes as a model for outer membranes of gram-negative bacteria. FEBS Lett 449: 221-224, 1999.

40. Deshayes S, Plénat T, Aldrian-Herrada G, Divita G, Le Grimellec C and Heitz F: Primary amphipathic cell-penetrating peptides: Structural requirements and interactions with model membranes. Biochemistry 43: 7698-7706, 2004.

41. Regberg J, Eriksson JN and Langel U: Cell-penetrating peptides: From cell cultures to in vivo applications. Front Biosci (Elite Ed) 5: 509-516, 2013

42. Safety and efficacy study of AVI-5126 when used on vein grafts before use in heart by-pass graft surgery (CABG). https://clinicaltrials.gov/ct2/show/NCT00451256, 2009.

43. Safety and efficacy study of KAI-1678 to treat pain in subjects with postherpetic neuralgia. https://clinicaltrials.gov/ct2/show/ NCT01106716, 2010

44. Safety and efficacy study of KAI-1678 to treat pain in subjects with spinal cord injury. https://clinicaltrials.gov/ct2/show/ NCT01135108, 2010.

45. Safety and efficacy study of KAI-1678 to treat subjects with postoperative pain. https://clinicaltrials.gov/ct2/show/NCT01015235, 2011.

46. Efficacy of AM-111 in patients with acute sensorineural hearing loss. https://clinicaltrials.gov/ct2/show/NCT00802425, 2014.

47. Safety and efficacy study of RT001 to treat moderate to severe lateral canthal lines. https://clinicaltrials.gov/ct2/show/ NCT00888914, 2013.

48. Safety, tolerability and PK of a single iv infusion of 10,40 , and $80 \mu \mathrm{g} / \mathrm{kg}$ XG-102 administered to healthy volunteers. https://clinicaltrials.gov/ct2/show/NCT01570205, 2012.

49. Efficacy and safety of XG-102 in reduction of post-cataract surgery intraocular inflammation. https://clinicaltrials.gov/ct2/ show/NCT02235272, 2015

50. AM-111 in the treatment of acute inner ear hearing loss (HEALOS). https://clinicaltrials.gov/ct2/show/NCT02561091, 2014. 
51. Efficacy and safety of AM-111 as acute sudden sensorineural hearing loss treatment (ASSENT). https://clinicaltrials.gov/ct2/ show/NCT02809118, 2017.

52. Bakhtiyari S, Haghani K, Basati G and Karimfar MH: siRNA therapeutics in the treatment of diseases. Ther Deliv 4: 45-57, 2013.

53. Nakase I, Tanaka G and Futaki S: Cell-penetrating peptides (CPPs) as a vector for the delivery of siRNAs into cells. Mo Biosyst 9: 855-861, 2013.

54. Wierzbicki PM, Kogut-Wierzbicka M, Ruczynski J, Siedlecka-Kroplewska K, Kaszubowska L, Rybarczyk A, Alenowicz M, Rekowski P and Kmiec Z: Protein and siRNA delivery by transportan and transportan 10 into colorectal cancer cell lines. Folia Histochem Cytobiol 52: 270-280, 2014

55. Moschos SA, Jones SW, Perry MM, Williams AE, Erjefalt JS, Turner JJ, Barnes PJ, Sproat BS, Gait MJ and Lindsay MA: Lung delivery studies using siRNA conjugated to TAT(48-60) and penetratin reveal peptide induced reduction in gene expression and induction of innate immunity. Bioconjug Chem 18: 1450-1459, 2007.

56. Turner JJ, Jones S, Fabani MM, Ivanova G, Arzumanov AA and Gait MJ: RNA targeting with peptide conjugates of oligonucleotides, siRNA and PNA. Blood Cells Mol Dis 38: 1-7, 2007.

57. Muratovska A and Eccles MR: Conjugate for efficient delivery of short interfering RNA (siRNA) into mammalian cells. FEBS Lett 558: 63-68, 2004

58. Davidson TJ, Harel S, Arboleda VA, Prunell GF, Shelanski ML, Greene LA and Troy CM: Highly efficient small interfering RNA delivery to primary mammalian neurons induces MicroRNA-like effects before mRNA degradation. J Neurosci 24: 10040-10046, 2004.

59. Chiu YL, Ali A, Chu CY, Cao H and Rana TM: Visualizing a correlation between siRNA localization, cellular uptake, and RNAi in living cells. Chem Biol 11: 1165-1175, 2004.

60. Turner JJ, Williams D, Owen D and Gait MJ: Disulfide conjugation of peptides to oligonucleotides and their analogs. Current protocols in nucleic acid chemistry Chapter 4: Unit 4.28, 2006.

61. Huang YW, Lee HJ, Tolliver LM and Aronstam RS: Delivery of nucleic acids and nanomaterials by cell-penetrating peptides: Opportunities and challenges. Biomed Res Int 2015: 834079, 2015.

62. Crowet JM, Lins L, Deshayes S, Divita G, Morris M, Brasseur R and Thomas A: Modeling of non-covalent complexes of the cell-penetrating peptide CADY and its siRNA cargo. Biochim Biophys Acta 1828: 499-509, 2013.

63. Crombez L, Morris MC, Dufort S, Aldrian-Herrada G, Nguyen Q, Mc Master G, Coll JL, Heitz F and Divita G: Targeting cyclin B1 through peptide-based delivery of siRNA prevents tumour growth. Nucleic Acids Res 37: 4559-4569, 2009.

64. Kadkhodayan S, Jafarzade BS, Sadat SM, Motevalli F, Agi E and Bolhassani A: Combination of cell penetrating peptides and heterologous DNA prime/protein boost strategy enhances immune responses against HIV-1 Nef antigen in BALB/c mouse model. Immunol Lett 188: 38-45, 2017.

65. Bivalkar-Mehla S, Mehla R and Chauhan A: Chimeric peptide-mediated siRNA transduction to inhibit HIV-1 infection. J Drug Target 25: 307-319, 2017

66. Kato T, Yamashita H, Misawa T, Nishida K, Kurihara M, Tanaka M, Demizu Y and Oba M: Plasmid DNA delivery by arginine-rich cell-penetrating peptides containing unnatural amino acids. Bioorg Med Chem 24: 2681-2687, 2016.

67. Rudolph C, Plank C, Lausier J, Schillinger U, Müller RH and Rosenecker J: Oligomers of the arginine-rich motif of the HIV-1 TAT protein are capable of transferring plasmid DNA into cells J Biol Chem 278: 11411-11418, 2003.

68. Rádis-Baptista G, Campelo IS, Morlighem JR, Melo LM and Freitas VJ: Cell-penetrating peptides (CPPs): From delivery of nucleic acids and antigens to transduction of engineered nucleases for application in transgenesis. J Biotechnol 252: 15-26, 2017

69. Nagy A: Cre recombinase: The universal reagent for genome tailoring. Genesis 26: 99-109, 2000 .

70. Jo D, Nashabi A, Doxsee C, Lin Q, Unutmaz D, Chen J and Ruley HE: Epigenetic regulation of gene structure and function with a cell-permeable Cre recombinase. Nat Biotechnol 19: 929-933, 2001

71. Wadia JS, Stan RV and Dowdy SF: Transducible TAT-HA fusogenic peptide enhances escape of TAT-fusion proteins after lipid raft macropinocytosis. Nat Med 10: 310-315, 2004

72. Hashimoto M, Taniguchi M, Yoshino S, Arai S and Sato K: $S$ Phase-preferential Cre-recombination in mammalian cells revealed by HIV-TAT-PTD-mediated protein transduction. J Biochem 143: 87-95, 2008
73. Xu Y, Liu S, Yu G, Chen J, Chen J, Xu X, Wu Y, Zhang A, Dowdy SF and Cheng G: Excision of selectable genes from transgenic goat cells by a protein transducible TAT-Cre recombinase. Gene 419: 70-74, 2008

74. De Coupade C, Fittipaldi A, Chagnas V, Michel M, Carlier S, Tasciotti E, Darmon A, Ravel D, Kearsey J, Giacca M, et al: Novel human-derived cell-penetrating peptides for specific subcellular delivery of therapeutic biomolecules. Biochem J 390: 407-418, 2005

75. Gitton Y, Tibaldi L, Dupont E, Levi G and Joliot A: Efficient CPP-mediated Cre protein delivery to developing and adult CNS tissues. BMC Biotechnol 9: 40, 2009.

76. Sonsteng KM, Prigge JR, Talago EA, June RK and Schmidt EE: Hydrodynamic delivery of Cre protein to lineage-mark or time-stamp mouse hepatocytes in situ. PLoS One 9: e91219, 2014.

77. Gaj T, Guo J, Kato Y, Sirk SJ and Barbas CF III: Targeted gene knockout by direct delivery of zinc-finger nuclease proteins. Nat Methods 9: 805-807, 2012.

78. Chen Z, Jaafar L, Agyekum DG, Xiao H, Wade MF, Kumaran RI, Spector DL, Bao G, Porteus MH, Dynan WS, et al: Receptor-mediated delivery of engineered nucleases for genome modification. Nucleic Acids Res 41: e182, 2013

79. Cornu TI, Thibodeau-Beganny S, Guhl E, Alwin S, Eichtinger M, Joung JK and Cathomen T: DNA-binding specificity is a major determinant of the activity and toxicity of zinc-finger nucleases. Mol Ther 16: 352-358, 2008.

80. Pruett-Miller SM, Reading DW, Porter SN and Porteus MH: Attenuation of zinc finger nuclease toxicity by small-molecule regulation of protein levels. PLoS Genet 5: e1000376, 2009.

81. Puria R, Sahi S and Nain V: HER2 ${ }^{+}$breast cancer therapy: By CPP-ZFN mediated targeting of mTOR? Technol Cancer Res Treat 11: 175-180, 2012

82. Nain V, Sahi S and Verma A: CPP-ZFN: A potential DNA-targeting anti-malarial drug. Malar J 9: 258, 2010.

83. Liu J,Gaj T,Patterson JT, Sirk SJ and Barbas CFIII: Cell-penetrating peptide-mediated delivery of TALEN proteins via bioconjugation for genome engineering. PLoS One 9: e85755, 2014.

84. Horvath P and Barrangou R: CRISPR/Cas, the immune system of bacteria and archaea. Science 327: 167-170, 2010.

85. Selle K and Barrangou R: Harnessing CRISPR-Cas systems for bacterial genome editing. Trends Microbiol 23: 225-232, 2015.

86. Harms DW, Quadros RM, Seruggia D, Ohtsuka M, Takahashi G, Montoliu L and Gurumurthy CB: Mouse genome editing using the CRISPR/Cas system. Curr Protoc Hum Genet 83: 15.7.1-15.7.27, 2014.

87. Bortesi L and Fischer R: The CRISPR/Cas9 system for plant genome editing and beyond. Biotechnol Adv 33: 41-52, 2015.

88. Park A, Hong P, Won ST, Thibault PA, Vigant F, Oguntuyo KY, Taft JD and Lee B: Sendai virus, an RNA virus with no risk of genomic integration, delivers CRISPR/Cas9 for efficient gene editing. Mol Ther Methods Clin Dev 3: 16057, 2016.

89. Suresh B, Ramakrishna S and Kim H: Cell-penetrating peptide-mediated delivery of Cas9 protein and guide RNA for genome editing. Methods Mol Biol 1507: 81-94, 2017.

90. Langel U (ed): Handbook of Cell-Penetrating Peptides. 2nd edition. Taylor and Francis Group, 2006

91. Saar K, Lindgren M,Hansen M,Eiríksdóttir E, Jiang Y, RosenthalAizman K, Sassian M and Langel U: Cell-penetrating peptides: A comparative membrane toxicity study. Anal Biochem 345: 55-65, 2005.

92. Suhorutsenko J, Oskolkov N, Arukuusk P, Kurrikoff K, Eriste E, Copolovici DM and Langel U: Cell-penetrating peptides, PepFects, show no evidence of toxicity and immunogenicity in vitro and in vivo. Bioconjug Chem 22: 2255-2262, 2011.

93. Amantana A, Moulton HM, Cate ML, Reddy MT, Whitehead T, Hassinger JN, Youngblood DS and Iversen PL: Pharmacokinetics, biodistribution, stability and toxicity of a cell-penetrating peptide-morpholino oligomer conjugate. Bioconjug Chem 18: 1325-1331, 2007.

94. Maiolo JR, Ferrer M and Ottinger EA: Effects of cargo molecules on the cellular uptake of arginine-rich cell-penetrating peptides. Biochim Biophys Acta 1712: 161-172, 2005.

95. Cox DB, Platt RJ and Zhang F: Therapeutic genome editing: Prospects and challenges. Nat Med 21: 121-131, 2015.

96. Yin H, Song CQ, Dorkin JR, Zhu LJ, Li Y, Wu Q, Park A, Yang J, Suresh S, Bizhanova A, et al: Therapeutic genome editing by combined viral and non-viral delivery of CRISPR system components in vivo. Nat Biotechnol 34: 328-333, 2016.

This work is licensed under a Creative Commons

Attribution-NonCommercial-NoDerivatives 4.0 International (CC BY-NC-ND 4.0) License. 